\title{
Bilirubin-Induced Changes in Brain Energy Metabolism after Osmotic Opening of the Blood-Brain Barrier
}

\author{
RICHARD P. WENNBERG, BARBRO B. JOHANSSON, JAROSLAVA FOLBERGROVÁ, AND \\ BO K. SIESJÖ
}

Department of Neurology [B.B.J.] and Laboratory for Experimental Brain Research [B.K.S.], University of Lund, Lund, Sweden; Department of Pediatrics, University of California, Davis [R.P.W.] Davis, California 95616; and Institute of Physiology, Czechoslovak Academy of Science, Prague, Czechoslovakia [J.F.]

\begin{abstract}
Acute and residual effects of blood-brain barrier disruption and bilirubin on brain metabolism were studied in a rat model after osmotic opening of the bloodbrain barrier under pentobarbital anesthesia. Arabinose $(1.5 \mathrm{M})$ was infused via the right external carotid artery over $30 \mathrm{~s}$, resulting in opening of the barrier within the right hemisphere. Two min later, bilirubin was infused i.v. over $3 \mathrm{~min}$, raising the serum bilirubin concentration to $37-44 \mathrm{mg} / \mathrm{dL}(633-752 \mu \mathrm{mol} / \mathrm{L})$. The animals were euthanized at 15 min or $4 \mathrm{~h}$ by freezing the brain in situ. Opening the blood-brain barrier produced small changes in cerebral energy metabolism in some animals at 15 min. Compared with saline-infused control animals, two out of nine rats had decreased brain phosphocreatine and three out of nine developed increased brain lactate levels. Infusion of bilirubin in rats with a disrupted blood-brain barrier produced profound decreases in brain energy metabolites, glucose, and glycogen and a markedly increased lactate/ pyruvate ratio at $15 \mathrm{~min}$. The markedly increased lactate in the presence of normal or low pyruvate in bilirubintreated animals indicates accumulation of NADH and probably reflects severe mitochondrial dysfunction. Four $h$ after the arabinose/bilirubin infusions, the barrier would be expected to be repaired and bilirubin levels were negligible, but two out of five arabinose and three out of six bilirubin rats continued to have severely altered brain metabolism indicating residual brain injury in some animals. (Pediatr Res 30: 473-478, 1991)
\end{abstract}

Abbreviations

PCr, phosphocreatine

BP, blood pressure

The pathogenesis of irreversible bilirubin toxicity has not been established. In vitro, bilirubin uncouples oxidative phosphorylation and, at higher concentrations, inhibits respiration in isolated brain and liver mitochondria (1-5), various tissue homogenates (6-9), and cell culture (10-12). Neuronal mitochondrial abnormalities, including intramitochondrial glycogen-containing vacuoles, have been observed in congenitally jaundiced homozygous (jj) Gunn rats as early as $2 \mathrm{~d}$ of age $(13-15)$. On the other hand, several investigations have failed to demonstrate changes in

Received March 12, 1991; accepted July 3, 199 I

Correspondence and reprint requests: Richard P. Wennberg, M.D., Department of Pediatrics-TB193, University of California, Davis, Davis. CA 95616.

Supported by a grant from the Swedish Medical Research Council (14X-4968). cerebral energy metabolism after bilirubin infusion in animals $(16,17)$, even in the presence of neurologic signs. Diamond and Schmid (16) found normal oxidative phosphorylation in mitochondria isolated from the cerebella of symptomatic guinea pigs after a $1-h$ infusion of bilirubin and concluded that mitochondrial poisoning was probably not the critical factor in the development of bilirubin encephalopathy. A similar conclusion was drawn by Katoh et al. $(18,19)$, who found normal levels of ATP, NADH, and $\mathrm{NAD}^{+}$, but low levels of fructose diphosphate, pyruvate, and lactate in whole brains of 15-d old Gunn rats treated with novobiocin. They suggested that, in vivo, bilirubin inhibits glycolysis without affecting mitochondrial function. Phosphofructokinase as well as hexokinase is inhibited by bilirubin in vitro, but only at rather high bilirubin levels $(26-30 \mu \mathrm{mol} / \mathrm{L})(18)$.

A number of factors may contribute to this confusing picture of bilirubin toxicity. Kernicterus involves specific neurons and nuclei, so that differential effects may be seen in adjacent areas and abnormalities may not be detected using large tissue samples, e.g. Diamond and Schmid (16). McCandless and Abel (20) induced severe ataxia in Gunn rats by infusing a bilirubinalbumin binding competitor and measured metabolites in dissected freeze-dried sections of cerebella. ATP and PCr were decreased in Purkinje cell rich layers but not in molecular or granular layers, whereas glycogen and glucose were increased in all three layers. Furthermore, the metabolic response of a cell to bilirubin may vary with dose and duration of exposure. Metabolic changes may be secondary to cellular adjustments to sublethal bilirubin toxicity or reflect direct inhibition of metabolic pathways.

This study was designed to examine 1 ) whether bilirubin can rapidly and, by implication, directly affect brain energy metabolism in vivo, and 2) whether induced metabolic changes are sustained after the bilirubin exposure is withdrawn. Hyperbilirubinemia was induced by i.v. infusion of bilirubin after osmotic opening of the blood-brain barrier. By opening the blood-brain barrier, the model facilitated rapid equilibration of bilirubin between serum and brain binding and circumvented to a large extent the problems of sampling, inasmuch as a large cell population was exposed to bilirubin. Under these conditions, we found evidence of severe bilirubin-induced mitochondrial dysfunction.

\section{MATERIALS AND METHODS}

Experimental design and rationale. Anesthetized SpragueDawley rats were divided into three groups: arabinose controls (14 animals) received a $30-\mathrm{s}$ intracarotid infusion $1.5 \mathrm{M}$ arabinose to open the blood-brain barrier. Bilirubin-treated animals ( 15 rats) were infused with bilirubin i.v. after osmotic opening of the blood-brain barrier. Saline controls (six rats) received a 30 -s intracarotid infusion of isotonic saline. Animals were killed 
at either $15 \mathrm{~min}$ ( $10 \mathrm{~min}$ after completing the bilirubin infusion) to determine acute changes in brain metabolism, or $4 \mathrm{~h}$ later to evaluate longer term metabolic consequences of opening the blood-brain barrier and exposure to bilirubin.

The animal preparation was a modification of that described by Rapoport et al. $(21,22)$, who reported that intracarotid infusion of $1.6 \mathrm{M}$ arabinose at a rate of $0.12 \mathrm{~mL} \cdot \mathrm{s}^{-1}$ for $30 \mathrm{~s}$ opened the ipsilateral blood-brain barrier of rats in approximately two thirds of the animals. In our experiment, we reduced the infusion rate to $0.043 \mathrm{~mL} \cdot \mathrm{s}^{-1}$ for $30 \mathrm{~s}$ because we ligated the pterygomandibular artery, a major branch of the carotid artery in rats. In a pilot study (23), we observed that infusing $1.9 \mathrm{M}$ arabinose at this rate significantly impaired cerebral metabolism in the ipsilateral hemisphere with minimal or no change in the energy level of the contralateral hemisphere. Infusion of bilirubin further decreased ATP, uridine triphosphate, and guanosine triphosphate levels. To minimize the metabolic effects of barrier disruption, we initially identified the lowest arabinose concentration/flow rate conditions likely to produce barrier opening. Arabinose $(1.5 \mathrm{M})$ infused at a rate of $0.043 \mathrm{~mL} \cdot \mathrm{s}^{-1}$ opened the blood-brain barrier in five of seven rats. EEG changes, previously found to coincide with successful barrier opening (24), were frequently absent under these conditions despite deep Evans blue staining, suggesting that osmolality of the infusate contributes to the EEG change.

Surgical preparation. Nonfasted male Sprague-Dawley rats weighing 280-340 g (mean $312 \mathrm{~g}$ ) were anesthetized with sodium pentobarbital ( $\sim 50 \mathrm{mg}$ intraperitoneally). Polyethylene catheters (PE50) were placed in the femoral vein for saline/bilirubin infusions and in the femoral artery for blood sampling and blood pressure monitoring. A Portex PE 10 catheter connected to PE50 tubing was then inserted into the right external carotid artery with the tip lying near the carotid bifurcation for saline or arabinose infusion. The pterygopalatine artery, which normally receives about $50 \%$ of the internal carotid blood flow, was ligated to assure delivery of the infusate to the brain. The femoral artery catheter was attached to a pressure transducer for measuring blood pressure. The calvarium was exposed and paired cortical screw electrodes were placed over right and left hemispheres with a ground electrode placed over the nose.

Experimental procedure. Before intracarotid infusion, the rat was intubated and placed on a small animal ventilator. Baseline EEG recording, rectal temperature, and BP readings were obtained, and arterial blood gases, $\mathrm{pH}$, and blood glucose were measured. The blood-brain barrier was then opened by infusing

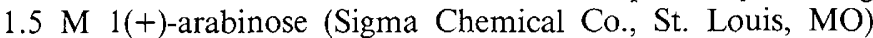
through the external carotid artery at a rate of $2.6 \mathrm{~mL} / \mathrm{min}$ over $30 \mathrm{~s}$ (total volume $1.3 \mathrm{~mL}$ ). Control animals received an equal volume of saline by carotid infusion. Infusates were warmed to $37^{\circ} \mathrm{C}$, administered by a constant infusion pump, and filtered inline through a $0.45-\mu \mathrm{m}$ Millipore filter. One and a half min after the carotid infusion, $3.0 \mathrm{~mL}$ bilirubin solution (12-14 mg) or an equal volume of saline was infused through the femoral vein catheter at a rate of $1.0 \mathrm{~mL} / \mathrm{min}$ for $3 \mathrm{~min}$. Bilirubin (Sigma Chemical Co.) was dissolved in $\sim 0.5 \mathrm{~mL} 0.1 \mathrm{~N} \mathrm{NaOH}$ and diluted to $3.0 \mathrm{~mL}$ with saline, and $\mathrm{pH}$ was adjusted to $9.0-9.8$ with dilute $\mathrm{HCl}$. The solution was prepared immediately before use and protected from light by wrapping syringe and catheter in aluminum foil. Blood pressure was recorded continuously. Cortical electrical activity over each hemisphere was recorded continuously during intracarotid and i.v. infusions, and intermittently thereafter for $10 \mathrm{~min}$ on a Mingograf polygraph (Elema, Stockholm, Sweden). Blood gases, blood glucose, and serum bilirubin were measured at $7 \mathrm{~min}$ ( $2 \mathrm{~min}$ after bilirubin infusion) and, in most cases, just before the rats were killed. At 15 min or $4 \mathrm{~h}$, electrodes were removed, and the brain was frozen in situ (25). The brain was removed by chisel and stored at $-80^{\circ} \mathrm{C}$ until analyzed.

Metabolites were analyzed from $\sim 20 \mathrm{mg}$ samples obtained from the right midparietal cortex at least $3 \mathrm{~mm}$ lateral from midline. Samples were dissected and extracted with $\mathrm{HCl}$-methanol at $-22^{\circ} \mathrm{C}$ and subsequently with perchloric acid at $0^{\circ} \mathrm{C}$, as previously described (26). Metabolites were measured with enzymatic fluorimetric techniques of Lowry and Passonneau (27). The adenylate energy charge (E.C.), reflecting the balance between production and utilization of energy (28), was calculated as:

$$
\text { E.C. }=\frac{[\mathrm{ATP}]+0.5[\mathrm{ADP}]}{[\mathrm{ATP}]+[\mathrm{ADP}]+[\mathrm{AMP}]}
$$

EEG was interpreted according to degree of amplitude and frequency change using a simple 1 to $3+$ scoring system (24) by a neurologist blinded to treatment groups.

Statistical analyses was performed using analysis of variance and Newman-Keuls method for evaluating mean differences. Because of potential variations in barrier opening by arabinose, differences between arabinose and arabinose/bilirubin groups were also analyzed by nonparametric analysis (Mann-Whitney ranking). A value of $p<0.05$ was accepted as statistically significant.

\section{RESULTS}

The acute effects of intracarotid infusion of saline, arabinose, or arabinose + i.v. bilirubin on brain metabolism are summarized in Table 1. Energy metabolite levels obtained about $15 \mathrm{~min}$ after intracarotid infusion of saline were similar to reported values in pentobarbital anesthetized rats (29) although two out of six saline control animals had slight elevations in lactate and pyruvate. Osmotic opening of the blood-brain barrier acutely decreased $\mathrm{PCr}$ (two out of nine) and raised pyruvate and lactate concentrations (three out of nine) in some rats, but group values were not significantly different from values in saline controls. By contrast, infusion of bilirubin to maximum levels of $37-44 \mathrm{mg} /$ $\mathrm{dL}(632-752 \mu \mathrm{mol} / \mathrm{L})$ had a profound immediate effect on energy metabolites in brain. PCr levels at $15 \mathrm{~min}$ fell to about $40 \%$ of control values and ATP dropped to about $60 \%$ of controls, whereas ADP and AMP increased. The calculated adenylate energy charge decreased proportionately. The decrease in high energy metabolites was accompanied by a dramatic drop in brain glucose, brain/blood glucose ratio, and glycogen and an increase in brain lactate. Glucose-6-phosphate and pyruvate decreased slightly in the more severely affected rats, but mean values were similar to saline controls. In arabinose-treated rats, all animals with an elevated lactate had an elevated pyruvate as well. In contrast, four out of five bilirubin-treated rats with high lactate $(9-18 \mu \mathrm{mol} / \mathrm{L})$ had normal or depressed pyruvate, suggesting that different processes were responsible for the acute metabolic abnormalities induced by barrier opening and bilirubin (Table 2).

In both arabinose and bilirubin/arabinose groups, energy charge was maintained in the face of dropping brain glucose until very low glucose levels were reached (Fig. 1). High lactate levels persisted even at very low glucose levels, suggesting that bilirubin (and opening of the barrier) resulted in increased glucose utilization in an attempt to sustain energy levels. Increased glucose utilization might occur with either increased energy needs or inhibition of energy production in mitochondria. The high lactate/pyruvate ratio in the bilirubin group (Fig. 2) suggests that the latter problem predominates in the bilirubin-treated animals.

Considerable variation in the severity of response was observed in bilirubin-treated rats (Table 2). The magnitude of metabolic changes had no relationship to the peak bilirubin level achieved. This suggests that differences in metabolic response are most likely due to variations in blood-brain barrier disruption and therefore exposure to bilirubin. Because variations in barrier permeability could skew mean values, differences between arabinose and arabinose/bilirubin groups were also analyzed using a nonparametric test (Mann-Whitney). Significant differences were found with respect to ATP, ADP, AMP, $\mathrm{PCr}$, adenylate 
Table 1. Energy metabolites 15 min after intracarotid infusion of saline, arabinose $(1.5 \mathrm{M})$, or arabinose followed by i.v. bilirubin $(50 \mathrm{mg} / \mathrm{kg})^{*}$

\begin{tabular}{|c|c|c|c|}
\hline Metabolite & $\begin{array}{l}\text { Saline } \\
(n=6)\end{array}$ & $\begin{array}{c}\text { Arabinose } \\
(n=9)\end{array}$ & $\begin{array}{c}\text { Arabinose }+ \text { bilirubin } \\
(n=9)\end{array}$ \\
\hline ATP & $2.83 \pm 0.05$ & $2.76 \pm 0.09$ & $1.72 \pm 0.33 \dagger$ \\
\hline ADP & $0.312 \pm 0.010$ & $0.314 \pm 0.010$ & $0.509 \pm 0.050 \dagger$ \\
\hline AMP & $0.070 \pm 0.014$ & $0.074 \pm 0.009$ & $0.563 \pm 0.171 \dagger$ \\
\hline$\sum \mathrm{AMP}, \mathrm{ADP}, \mathrm{ATP}$ & $3.21 \pm 0.04$ & $3.15 \pm 0.07$ & $2.80 \pm 0.14 \uparrow$ \\
\hline E.C. & $0.930 \pm 0.006$ & $0.925 \pm 0.007$ & $0.677 \pm 0.086 \dagger$ \\
\hline $\mathrm{PCr}$ & $4.93 \pm 0.14$ & $4.66 \pm 0.18$ & $2.04 \pm 0.51 \dagger$ \\
\hline Creatine & $5.63 \pm 0.27$ & $5.74 \pm 0.17$ & $8.05 \pm 0.41 \dagger$ \\
\hline Glycogen & $2.82 \pm 0.29$ & $2.41 \pm 0.45$ & $1.20 \pm 0.40 \dagger$ \\
\hline Glucose & $2.95 \pm 0.26$ & $2.75 \pm 0.32$ & $1.02 \pm 0.32 \dagger$ \\
\hline Glucose-6-phosphate & $0.137 \pm 0.023$ & $0.135 \pm 0.028$ & $0.099 \pm 0.020$ \\
\hline Lactate & $2.27 \pm 0.94$ & $3.77 \pm 1.41$ & $10.55 \pm 1.67 \dagger$ \\
\hline Pyruvate & $0.091 \pm 0.016$ & $0.107 \pm 0.026$ & $0.077 \pm 0.015$ \\
\hline
\end{tabular}

* Mean values in $\mathrm{mmol} / \mathrm{kg}$ brain tissue \pm SEM. E.C., adenylate energy charge.

$\dagger$ Difference between means of bilirubin group and both arabinose and saline group is significant, $p<0.05$.

Table 2. Metabolic changes in individual rats after bilirubin and/or arabinose infusion*

\begin{tabular}{|c|c|c|c|c|c|c|c|c|c|c|}
\hline & E.C. & ATP & $\mathrm{PCr}$ & Glycogen & Glucose & Glucose-6-phosphate & Lactate & Pyruvate & Lactate/pyruvate & EEG $15^{\prime} \dagger$ \\
\hline $\begin{array}{l}\text { Controls } \\
\text { (median) }\end{array}$ & 0.930 & 2.83 & 4.93 & 2.82 & 2.95 & 0.137 & $\begin{array}{r}2.27 \\
(1.06)\end{array}$ & $\begin{array}{c}0.091 \\
(0.069)\end{array}$ & $\begin{array}{c}20 \\
(15)\end{array}$ & \\
\hline \multicolumn{11}{|l|}{ Arabinose } \\
\hline 7 & 0.942 & 3.08 & 4.96 & 3.93 & 4.28 & 0.112 & 1.17 & 0.054 & 22 & 0 \\
\hline 8 & 0.940 & 2.98 & 5.02 & 3.14 & 2.61 & 0.061 & 1.51 & 0.096 & 16 & 0 \\
\hline 1 & 0.939 & 2.83 & 4.72 & 2.98 & 2.55 & 0.107 & 0.87 & 0.057 & 15 & \pm \\
\hline 2 & 0.938 & 2.98 & 5.10 & 3.44 & 2.79 & 0.089 & 0.84 & 0.056 & 15 & $1+$ \\
\hline 4 & 0.935 & 2.89 & 5.28 & 3.61 & 3.03 & 0.087 & 0.79 & 0.066 & 12 & $3+$ \\
\hline 9 & 0.925 & 2.68 & 4.71 & 2.46 & 2.89 & 0.099 & 1.55 & 0.049 & 32 & 0 \\
\hline 3 & 0.917 & 2.67 & 4.10 & 1.06 & 1.08 & 0.134 & 5.78 & 0.125 & 46 & 0 \\
\hline 6 & 0.915 & 2.50 & 4.50 & 0.67 & 3.83 & 0.340 & 11.16 & 0.286 & 39 & \pm \\
\hline 5 & 0.878 & 2.22 & 3.53 & 0.43 & 1.73 & 0.185 & 10.28 & 0.171 & 60 & $3+$ \\
\hline \multicolumn{11}{|l|}{ Bilirubin } \\
\hline 6 & 0.939 & 2.92 & 4.96 & 3.05 & 2.23 & 0.204 & 4.13 & 0.112 & 37 & \pm \\
\hline 1 & 0.916 & 2.65 & 3.47 & 2.30 & 3.09 & 0.159 & 5.65 & 0.151 & 37 & $\overline{0}$ \\
\hline 4 & 0.886 & 2.65 & 2.40 & 2.78 & 0.64 & 0.097 & 4.53 & 0.092 & 49 & 0 \\
\hline 9 & 0.830 & 2.31 & 2.80 & 1.43 & 0.66 & 0.129 & 9.02 & 0.064 & 141 & 0 \\
\hline 7 & 0.818 & 1.96 & 1.90 & 0.40 & 0.90 & 0.132 & 13.80 & 0.105 & 131 & $2+$ \\
\hline 3 & 0.637 & 1.39 & 1.28 & 0.20 & 0.43 & 0.072 & 11.33 & 0.063 & 180 & 0 \\
\hline 2 & 0.425 & 0.69 & 0.47 & 0.18 & 0.39 & 0.026 & 13.20 & 0.041 & 322 & $2+$ \\
\hline 5 & 0.364 & 0.56 & 0.63 & 0.30 & 0.41 & 0.045 & 18.03 & 0.029 & 622 & $3+$ \\
\hline 8 & 0.303 & 0.38 & 0.42 & 0.18 & 0.46 & 0.031 & 15.24 & 0.025 & 610 & $3+$ \\
\hline
\end{tabular}

* Animals were ranked according to decreasing energy charge in brain. For comparison, mean values for control animals are listed as well as median values where distribution was skewed. E.C., adenylate energy charge; EEG 15', EEG after 15 min.

$\dagger$ Graded as $0, \pm, 1+, 2+$, or $3+$, according to Ref. 24.

energy charge, glucose, glycogen, lactate, and lactate/pyruvate ratio, all with $p=0.01$ or less (two-tailed).

Baseline blood pressure ranged between 95 and $140 \mathrm{~mm} \mathrm{Hg}$. A transient decrease and/or increase in BP was observed in many animals after arabinose infusion. Sustained hypotension (70-90 $\mathrm{mm} \mathrm{Hg}$ ) was seen in two animals, one of which had a marked decrease in PCr. No animal had sustained BP below $40 \mathrm{~mm} \mathrm{Hg}$, a threshold previously reported to result in altered brain energy metabolism (30). Blood glucose levels ranged from 6.4 to 11.8 $\mathrm{mmol} / \mathrm{L}$. Arterial blood $\mathrm{pH}$ ranged from 7.29 to 7.43 , and $\mathrm{PCO}_{2}$ ranged from 5.5 to $7.5 \mathrm{kPa}$. Glucose levels and blood gas values were similar in the different experimental groups and did not correlate with metabolite levels in brain.

In a previous study (24), using nearly saturated arabinose solutions for carotid infusion, transient alterations in EEG almost invariably accompanied successful opening of the blood-brain barrier. That relationship was not observed in the present study using $1.5 \mathrm{M}$ arabinose, although the most severely affected rats had EEG changes both after arabinose infusion and during bilirubin infusion. EEG abnormalities with $2+$ or $3+$ changes (primarily a decrease in amplitude) occurred in four out of nine bilirubin-treated and two out of nine arabinose-treated animals. Distinct seizure patterns were not identified.

By $4 \mathrm{~h}$ postinfusion, brain and plasma levels of both anesthetics and bilirubin should be negligible (31), yet most of the animals remained very lethargic or obtunded. Both arabinose- and bilirubin-treated animals had altered brain metabolism, with increased lactate and decreased nucleotide triphosphates (Table 3). All animals tested had normoxemia, but some had a mixed respiratory-metabolic acidosis. In contrast to acute metabolic events, changes in brain ATP and lactate levels in individual rats at $4 \mathrm{~h}$ corresponded closely to the magnitude of EEG changes observed during the initial 15-min experimental period (Table 3). EEG was not recorded at $4 \mathrm{~h}$. Marked elevations in brain lactate were observed in three out of six bilirubin- and two out of five arabinose-treated animals. Histologic studies, performed on an additional four animals killed $4 \mathrm{~h}$ after bilirubin infusion demonstrated diffuse neuronal damage and diffuse neuronal histochemical staining for albumin, but no nuclear or cellular staining with bilirubin. Similar, but less severe findings were present in three out of four arabinose controls. 


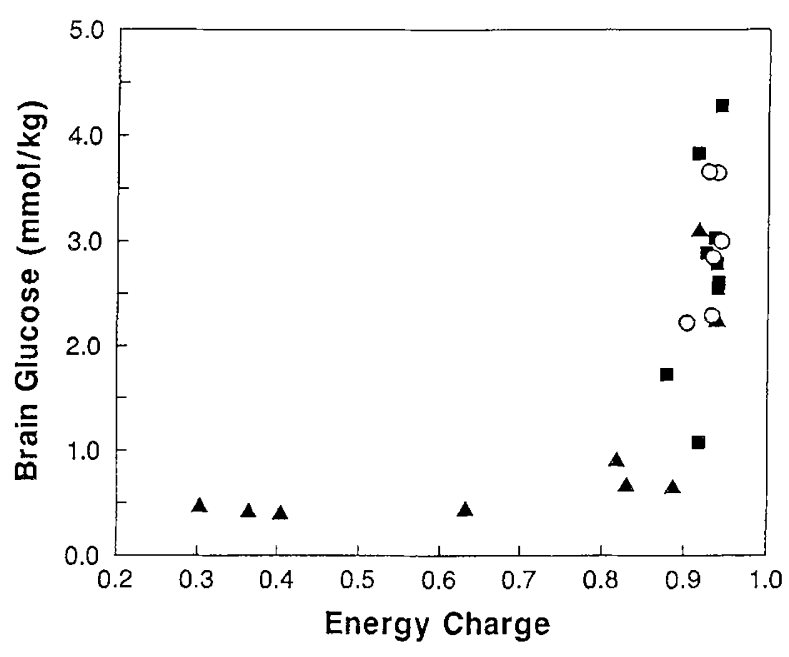

Fig. 1. Relationship of brain glucose concentration to adenylate energy charge in individual rats at $15 \mathrm{~min}$. $\mathrm{O}$, controls; $\mathbf{\square}$, arabinose; $\boldsymbol{\Lambda}$, arabinose + bilirubin. A similar relationship exists when brain glucose is expressed as brain/blood glucose ratio.

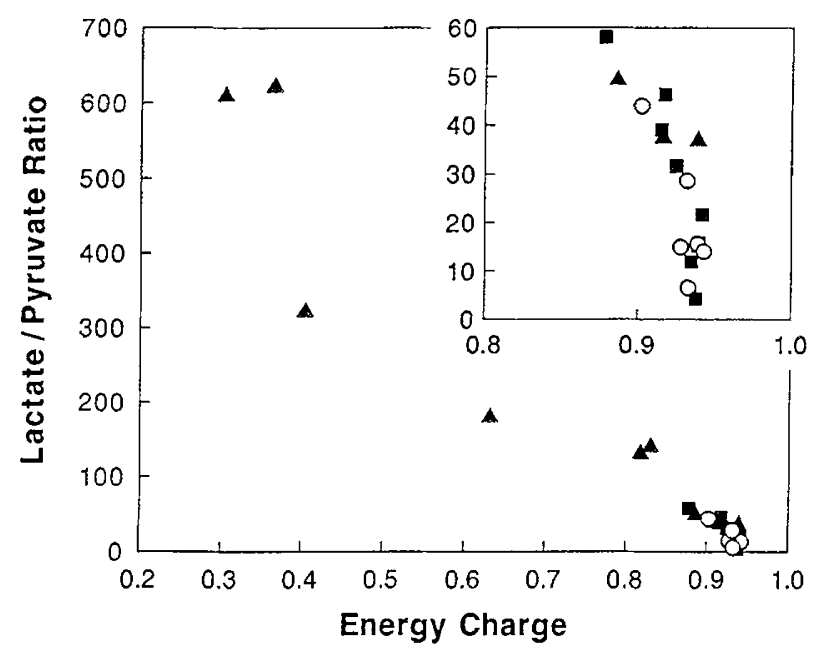

Fig. 2. Relationship of lactate/pyruvate ratio to adenylate energy charge in individual rats at $15 \mathrm{~min} . \mathrm{O}$, controls; $\boldsymbol{\square}$, arabinose; $\boldsymbol{\Lambda}$, arabinose + bilirubin. The expanded scale in the inserted graph illustrates the relationship at lower lactate/pyruvate ratios.

\section{DISCUSSION}

In the presence of a disrupted blood-brain barrier, hyperbilirubinemia induced a pronounced and immediate disturbance of energy metabolism in rat brain including depletion of energy charge, glucose, and glycogen and an increase in lactate and lactate/pyruvate ratio. The lactate/pyruvate ratio depends on the redox state of the cell as well as intracellular $\mathrm{pH}$. The extremely high lactate/pyruvate ratios observed in bilirubin-treated rats cannot be explained by an increase in hydrogen ion concentration alone, indicating a high $\mathrm{NADH} / \mathrm{NAD}+$ ratio. This pattern of disturbance is indicative of either severe ischemia or mitochondrial dysfunction involving a block in NADH transport or utilization (32). Osmotic opening of the blood-brain barrier is accompanied by an initial increase in cerebral blood flow lasting up to 6 min (33), followed by a decrease in flow associated with a mild vasogenic brain edema lasting up to $1 \mathrm{~h}(34,35)$. During this time there is uncoupling of cerebral blood flow and metabolism. An increase in glucose uptake and utilization has been reported to accompany osmotic opening of the barrier (34-36), possibly due in part to seizure activity (37). Brain glucose levels were decreased in only two out of nine arabinose-treated rats in this study, but glucose flux was not measured. The reported decrease in blood flow induced by hypertonic solutions is insufficient to produce ischemia, and bilirubin has no significant effect on cerebral blood flow in the presence of an intact bloodbrain barrier (38). Possible synergy between bilirubin and hyperosmolar opening of the barrier in decreasing cerebral blood flow, although not specifically excluded in this study, is unlikely. Thus, the observed metabolic effects are most consistent with severe mitochondrial dysfunction.

Mitochondrial dysfunction is also suggested by the observations of Ives et al., (39) who, using a similar animal model, measured bilirubin-induced changes in brain energy metabolites in rats by ${ }^{31} \mathrm{P}$ nuclear magnetic resonance spectroscopy. A $35 \%$ reduction in $\mathrm{PCr} /(\mathrm{PCr}+$ inorganic phosphate) ratio occurred at bilirubin levels of $483 \pm 52 \mu \mathrm{mol} / \mathrm{L}(28.3 \pm 3.0 \mathrm{mg} / \mathrm{dL})$ after hyperosmolar opening of the barrier, but there was no significant change in brain $\mathrm{pH}$. The absence of acidosis precludes a diagnosis of ischemia and supports the conclusion that the elevation of lactate in the presence of a low or normal pyruvate after bilirubin infusion represents intracellular accumulation of $\mathrm{NADH}$.

Although kinetic studies were not performed, metabolite concentrations and ratios found in these rats provide no evidence for inhibition of glycolysis or increased glycogen synthesis as suggested by Katoh-Semba and others $(18,19)$ using the Gunn rat model. Bilirubin-treated animals with minimal metabolic changes had normal levels of glucose-6-phosphate, pyruvate, and glycogen, with slight elevations in lactate. Moderately affected animals maintained near normal energy levels accompanied by a marked decrease in glucose and rise in lactate and lactate/ pyruvate ratio, and severely affected rats had a marked decrease in brain glycogen and glucose and increased lactate associated with a small decrease in pyruvate. By $4 \mathrm{~h}$ postinfusion, glycogen levels returned to near normal values in four of the six bilirubintreated rats, but increased glycogen did not occur. The accumulation of glycogen observed in Gunn rat brains cannot be explained by our findings and may represent a compensatory mechanism in sublethal chronic exposure to bilirubin.

The exact mechanism by which bilirubin produces mitochondrial dysfunction is unknown, and several molecular models describing bilirubin-membrane interaction have been proposed (40-42). Under physiologic conditions, tissue binding of bilirubin increases in direct proportion to the hydrogen ion concentration, indicating that it is governed by a single proton addition to bilirubin (43). Assuming an acid ionization constant for the propionic groups on bilirubin, Wennberg (43) proposed that the proton addition represents conversion of the bilirubin dianion to the monovalent anion. Given sufficient fluidity of the mitochondrial membrane, the monoanion might serve as a proton shuttle, altering the tightly controlled hydrogen ion gradient critical for oxidative phosphorylation (41). Experimental support for this model is provided by observations that bilirubin increases proton conductance in the inner membrane of rat liver mitochondria (44) and depolarizes mitochondria and plasma membranes in synaptosomes (45). Ostrow et al. (46) recently challenged the assumption that the dianion predominates at physiologic $\mathrm{pH}$, and proposed that the observed partitioning of bilirubin results from formation of the bilirubin acid (by adding a hydrogen ion to the monoanion). Tissue binding of bilirubin would then represent bilirubin acid-lipid complexes that might disturb mitochondrial function by disordering membrane lipid organization. Lipid-protein interactions modulate many transmembrane protein transport systems, e.g. $\mathrm{Ca}^{+}$ATPase (47), and are sensitive to changes in lipid-protein environment. A third possible mechanism is specific binding of bilirubin to enzymes involved with mitochondrial function. McLoughlin and Howell (48) found that bilirubin competitively inhibits purified mitochondrial malate dehydrogenase with a rather low $\mathrm{k}_{\mathrm{i}}$ of $2 \mu \mathrm{M}$ with respect to NADH binding to the enzyme. Malate dehydrogenase participates in the malate-aspartate shuttle responsible for the transport of reducing equivalents across the inner membrane of the mitochondria. Inhibition of this enzyme would result in 
Table 3. Energy metabolites $4 \mathrm{~h}$ after intracarotid infusion of arabinose $(1.5 \mathrm{M})$ or arabinose followed by i.v. bilirubin $(50 \mathrm{mg} / \mathrm{kg})^{*}$

\begin{tabular}{|c|c|c|c|c|c|c|c|}
\hline No. & $\mathrm{EEG}\left(15^{\prime}\right) \dagger$ & ATP & E.C. & Glucose & Lactate & Pyruvate & Art pH $\ddagger$ \\
\hline \multicolumn{8}{|c|}{ Arabinose $4 \mathrm{~h}$} \\
\hline 1 & $3+$ & 1.25 & 0.821 & 1.46 & 25.7 & 0.159 & \\
\hline 2 & \pm & 2.88 & 0.944 & 3.64 & 2.2 & 0.121 & 7.43 \\
\hline 3 & 0 & 2.91 & 0.942 & 3.94 & 1.8 & 0.049 & 7.34 \\
\hline 4 & $1+$ & 2.97 & 0.937 & 1.22 & 6.5 & 0.152 & 7.42 \\
\hline 5 & $2+$ & 1.02 & 0.482 & 0.21 & 10.7 & 0.030 & 7.36 \\
\hline Mean & & $2.21 \pm 0.44$ & $0.825 \pm 0.09$ & $2.09 \pm 0.73$ & $9.4 \pm 4.4$ & $0.102 \pm 0.03$ & \\
\hline \multicolumn{8}{|c|}{ Arabinose + bilirubin $4 \mathrm{~h}$} \\
\hline 1 & 0 & 2.86 & 0.945 & 2.73 & 1.5 & 0.085 & \\
\hline 2 & $2+$ & 0.44 & 0.396 & $0.13 \S$ & 12.5 & 0.049 & 7.23 \\
\hline 3 & $3+$ & 0.14 & 0.484 & 0.52 & 23.6 & 0.007 & 7.19 \\
\hline 4 & \pm & 2.21 & 0.917 & 2.80 & 3.6 & 0.147 & 7.44 \\
\hline 5 & $2+$ & 1.20 & 0.854 & 3.89 & 16.9 & 0.268 & \\
\hline 6 & \pm & 2.55 & 0.929 & 3.33 & 4.2 & 0.117 & \\
\hline Mean & & $1.57 \pm 0.47$ & $0.754 \pm 0.10$ & $2.23 \pm 0.63$ & $10.4 \pm 3.6$ & $0.112 \pm 0.04$ & \\
\hline
\end{tabular}

* Values in $\mathrm{mmol} / \mathrm{kg}$ brain tissue. EEG $\left(15^{\prime}\right)$, EEG after $15 \mathrm{~min}$; E.C., adenylate energy charge.

$\dagger$ Graded as $0, \pm, 1+, 2+$, or $3+$, according to Ref. 24 .

$\ddagger$ Arterial blood $\mathrm{pH}$ at $4 \mathrm{~h}$.

$\S$ Hypoglycemic at time of sacrifice (blood glucose $2.8 \mathrm{mmol} / \mathrm{L}$ ).

the accumulation of NADH in cytoplasm, a high NADH/NAD ${ }^{+}$ ratio, and secondarily a high lactate/pyruvate ratio as seen in this study.

Osmotic opening of the blood-brain barrier in the absence of hyperbilirubinemia is not innocuous. In this experiment, metabolic sequelae of osmotic opening of the blood-brain barrier appeared to be more severe at $4 \mathrm{~h}$ than immediately after the hypertonic arabinose infusion, and there was a striking relationship between brain metabolism at $4 \mathrm{~h}$ and acute EEG changes after arabinose infusion. Immediate changes in brain metabolism with opening the blood-brain barrier have been reported to be small (49), consistent with our findings. Ives et al. (39) reported a greater decrease in brain energy levels from osmotic opening of the blood-brain barrier than we observed, possibly because they used a more hypertonic solution of arabinose $(1.8 \mathrm{M})$. Delayed diffuse neuronal injury after osmotic opening of the blood-brain barrier was observed by Salahuddin et al. $(50,51)$, who reported changes similar to those observed in our animals. Disruption of the barrier not only exposes brain to an acute hypertonic environment, but abolishes control of brain substrate and protection against potential toxins in serum. Opening the barrier in rats with elevated plasma glutamate levels produced severe delayed neuronal damage, which became apparent only 24-72 h later (52). Our findings support the proposition that opening the blood brain barrier, even in the absence of bilirubin, may produce brain injury.

Some caution is warranted in extrapolating the results of this study to the pathogenesis of kernicterus in human infants. The population of cortical cells examined in this study might respond differently to a bilirubin load than less mature cells in the traditional target nuclei of newborns. It is also possible that opening the blood-brain barrier creates an environment that alters cellular defense mechanisms leading to a different pattern of response to bilirubin than that seen with an intact blood-brain barrier. The effect of hyperbilirubinemia in the presence of an intact blood-brain barrier was not examined in our model because we considered it unlikely to alter brain. In the presence of an intact blood-brain barrier, short term exposure to very high serum bilirubin concentrations ( $1063 \mu \mathrm{mol} / \mathrm{L} ; 62 \mathrm{mg} / \mathrm{dL}$ ) failed to produce alterations in brain metabolism in the study of Ives et al. (39) and failed to alter electrocortical activity in rats exposed to similar levels for up to $1 \mathrm{~h}(24)$. The importance of the bloodbrain barrier in modulating susceptibility to bilirubin toxicity in newborns is unknown. It is also not known whether early neurologic signs of bilirubin poisoning, e.g. lethargy or altered brain- stem auditory evoked response, result from impaired energy metabolism or reflect an independent effect of bilirubin on cell function. Our data do not address the mechanism of reversible bilirubin effects in newborn infants, but they do support the proposal that bilirubin can severely inhibit mitochondrial function that may contribute to irreversible bilirubin toxicity.

Acknowledgments. The authors thank Anna-Lena Ohlsson and Madeleine Jakobsson for their skillful technical assistance.

\section{REFERENCES}

1. Zetterström R, Ernster L 1956 Bilirubin, an uncoupler or oxidative phosphorylation in isolated mitochondria. Nature 178:1335-1336

2. Ernster L 1961 The node of action of bilirubin on mitochondria. In: SassKortsak A (ed) Kernicterus. University of Toronto Press, Toronto, Canada pp 174-192

3. Menken M, Waggoner JC, Berlin NI 1966 The influence of bilirubin on oxidative phosphorylation and related reactions in brain and liver mitochondria: effect of protein-binding. J Neurochem 13:1241-1248

4. Mustafa MG, Cowger ML, King TE 1969 Effects of bilirubin on mitochondrial reactions. J Biol Chem 244:6403-6414

5. Noir BA Boveris A Garaza Pereira AM, Stoppani AOM 1972 Bilirubin: a multi-site inhibitor of mitochondrial respiration. FEBS Lett 27:270-274

6. Day RL 1954 Inhibition of brain respiration in vivo by bilirubin: reversal of inhibition by various means. Proc Soc Exp Biol Med 85:261-264

7. Waters WJ, Bowen WR 1955 Bilirubin encephalopathy: studies related 10 cellular respiration. Am J Dis Child 90:603

8. Day RL 1956 Further observations on the toxicity of heme pigments. Pediatrics 17:925-928

9. Bowen WR, Waters WJ 1957 Bilirubin encephalopathy: studies related to the site of inhibitory action on brain metabolism. Am J Dis Child 93:21-22

10. Quastel JH, Bickis IJ 1959 Metabolism of normal tissues and neoplasms in vitro. Nature 183:281-286

11. Cowger ML, Igo RP, Labbe RF 1965 The mechanism of bilirubin toxicity studied with purified respiratory enzyme and tissue culture systems. Biochemistry 4:2763-2770

12. Cowger ML 1971 Mechanism of bilirubin toxicity on tissue culture cells: factors that affect toxicity, reversibility by albumin, and comparison with other respiratory poisons and surfactants. Biochem Med 5:1-16

13. Schutta HS, Johnson L 1967 Bilirubin encephalopathy in the Gunn rat: a fine structure study of the cerebellar cortex. J Neuropathol Exp Neurol 26:377396

14. Schutta HS, Johnson L, Meville HE 1970 Mitochondrial abnormalities in bilirubin encephalopathy. J Neuropathol Exp Neurol 29:296-305

15. Karp WB, Moore PJ, Subramanyam SB, Brown DB 1982 Relationship of plasma total bilirubin, apparent unbound bilirubin and total albumin with cerebellar glycogen and abnormal Purkinje cells in the Gunn rat. Biol Neonate 41:294-304

16. Diamond I, Schmid R 1967 Oxidative phosphorylation in experimental bilirubin encephalopathy. Science 155:1288-1289

17. Brann BS IV, Stonestreet BS, Oh W, Cashore WJ 1987 The in vivo effect of bilirubin and sulfisoxazole on cerebral oxygen, glucose, and lactate metabolism in newborn piglets. Pediatr Res 22:135-140 
18. Katoh R. Kashiwamata S, Niwa F 1975 Studies on cellular toxicity of bilirubin: effect on the carbohydrate metabolism in the young rat brain. Brain Res 83:81-92

19. Katoh-Semba R 1976 Studies on cellular toxicity of bilirubin: effect on brain glycolysis in the young rat. Brain Res 113:339-348

20. McCandless DW, Abel MS 1980 The effect of unconjugated bilirubin on regional cerebellar energy metabolism. Neurobehav Toxicol 2:81-84

21. Rapoport SI. Fredericks WR, Ohno K, Pettigrew KD I 980 Quantitative aspects of reversible osmotic opening of the blood-brain barrier. Am J Physiol 238:R421-R431

22. Levine RL, Fredericks WR, Rapoport SI 1982 Entry of bilirubin into the brain due to opening of the blood-brain barrier. Pediatrics 69:255-259

23. Wennberg RP, Pal N, Bessman SP 1986 Effects of blood-brain barrier disruption and bilirubin on cerebral metabolism. Pediatr Res 20:469A(abstr)

24. Wennberg RP, Hance AJ 1986 Experimental encephalopathy: importance of total bilirubin, protein binding, and blood-brain barrier. Pediatr Res 20:789 792

25. Ponten U, Ratcheson RA, Salford LG, Siesjö BK 1973 Optimal freezing conditions for cerebral metabolites in rats. J Neurochem 21:1127-1138

26. Lowry OH, Passonneau JV 1972 A Flexible System of Enzymatic Analysis. Academic Press, New York

27. Folbergrová J, MacMillan V, Siesjö BK 1972 The effect of moderate and marked hypercapnia upon the energy state and upon the cytoplasmic $\mathrm{NADH} / \mathrm{NAD}^{+}$ratio of the rat brain. J Neurochem 19:2495-2505

28. Atkinson DE 1971 Adenine nucleotides as stoichiometric coupling agents in metabolism and as regulatory modifiers: the adenylate energy charge. In: Vogel HJ (ed) Metabolic Pathways: Metabolic Regulations. 3rd Ed. Vol V, Academic Press, New York, pp 1-2

29. Nilsson L, Siesjö BK 1974 Influence of anaesthetics on the balance between production and utilization of energy in the brain. $\mathbf{J}$ Neurochem 23:29-36

30. Siesjo BK, Zwetnow 1970 The effect of hypovolemic hypotension on extraand intracellular acid-base parameters and energy metabolites in the rat brain. Acta Physiol Scand 46:187-202

31. Levine RL, Fredericks WR, Rapoport SI 1985 Clearance of bilirubin from rat brain after reversible osmotic opening of the blood-brain barrier. Pediatr Res 19:1040-1043

32. Siesjö BK 1979 Brain Energy Metabolism. Wiley, New York, pp 345-522

33. Hardebo JE, Nilsson B 1980 Hemodynamic changes in brain caused by local infusion of hyperosmolar solutions, in particular relation to blood-brain barrier opening. Brain Res 181:49-59

34. Rapoport SI, Ohata M, London ED 1981 Cerebral blood flow and glucose utilization following opening of the blood-brain barrier and during maturation of the rat brain. Fed Proc 40:2322-2325

35. Pappius HM, Savaki HE, Fieschi C, Rapoport SI, Sokoloff L 1979 Osmotic opening of the blood-brain barrier and local cerebral glucose utilization. Ann Neurol 5:211-219

36. Rapoport SI, London ED, Fredericks WR, Dow-Edwards DL, Mahone PR 1981 Altered cerebral glucose utilization following blood-brain barrier opening by hypertonicity and hypertension. Exp Neurol 74:519-529
37. Fieschi C, Lenzi GL, Zanette E, Orzi F, Passero S 1980 Effects on EEG of the osmotic opening of the blood-brain barrier in rats. Life Sci 27:239-243

38. Burgess GH, Oh W, Bratlid D, Brubakk A-M, Cashore WJ, Stonestreet BS 1985 The effects of brain blood flow on brain bilirubin deposition in newborn piglets. Pediatr Res 19:691-696

39. Ives NK, Bolas NM, Gardiner RM 1989 The effects of bilirubin on brain energy metabolism during hyperosmolar opening of the blood-brain barrier: an in vivo study using ${ }^{31} \mathrm{P}$ nuclear magnetic resonance spectroscopy. Pediatr Res 26:356-361

40. Vázquez J, Garcia-Calvo M, Valdivieso F, Mayor F, Mayor Jr F 1988 Inter action of bilirubin with the synaptosomal plasma membranes. J Biol Chem 263:1255-1265

41. Wennberg RP 1990 Bilirubin encephalopathy: role of the blood-brain barrier. In: Johansson BB, Owman C, Widner H (eds) Pathophysiology of the Bloodbrain Barrier: Long Term Consequences of Barrier Dysfunction for the Brain, Fernström Foundation Series, Vol 14, Elsevier, Amsterdam, pp 269 278

42. Eriksen E, Danielsen H, Brodersen R 1981 Bilirubin-liposome interaction Binding of bilirubin dianion, protonization, and aggregation of bilirubin acid. J Biol Chem 256:4269-4274

43. Wennberg RP 1988 The importance of free bilirubin acid salt in bilirubin uptake by erythrocytes and mitochondria. Pediatr Res 23:443-447

44. Stumpf DA, Eguren LA, Parks JK 1985 Bilirubin increases mitochondrial inner membrane conductance. Biochem Med 34:226-229

45. Mayor Jr F, Diez-Guerra J, Valdiveso F, Mayor F 1986 Effect of bilirubin on the membrane potential of rat brain synaptosomes. J Neurochem 47:363369

46. Ostrow JD, Celic L, Mukerjee P 1988 Molecular and micellar associations in the pH-dependent stable and metastable dissolution of unconjugated bilirubin by bile salts. J Lipid Res 29:335-348

47. Deliconstantinos G 1988 Structure activity relationship of cholesterol and steroid hormones with respect to their effects on the $\mathrm{Ca}^{2+}$-stimulated ATPase and lipid fluidity of synaptosomal plasma membranes from dog and rabbit brain. Comp Biochem Physiol [B] 89:585-594

48. McLoughlin DJ, Howell ML 1987 Bilirubin inhibition of enzymes involved in the mitochondrial malate-aspartate shuttle. Biochim Biophys Acta 893:7-12

49. Johansson B, Siesjö BK 1977 Brain energy metabolism in angiotensin-induced acute hypertension in rats. Acta Physiol Scand 100:182-186

50. Salahuddin TS, Kalimo H, Johansson BB, Olsson Y 1988 Structural changes in the rat brain after carotid infusions of hyperosmolar solutions. An electron microscopic study. Acta Neuropathol [Berl] 77:5-13

51. Salahuddin TS, Johansson BB, Kalimo H Olsson Y 1988 Structural changes in the rat brain after carotid infusions of hyperosmolar solutions: a light microscopic and immunohistochemical study. Neuropathol Appl Neurobiol 14:467-482

52. Johansson BB, Nordborg C, Westergren I 1990 Neuronal injury after a transient opening of the blood-brain barrier: modifying factors: In Johansson BB Owman C, Widner H, (eds) Pathophysiology of the Blood-brain Barrier: Long Term Consequences of Barrier Dysfunction for the Brain. Fernström Foundation Series, Vol 14. Elsevier, Amsterdam, pp 145-157 